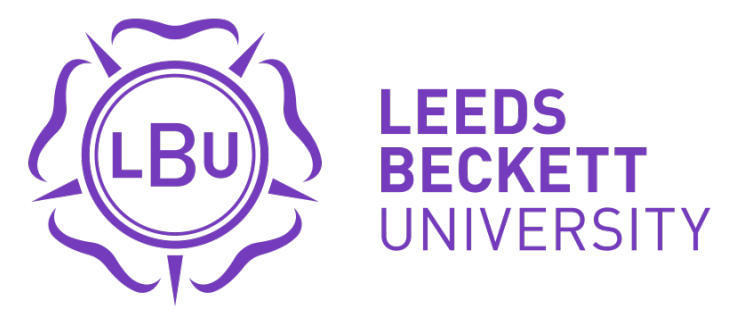

Citation:

Ajayi, SO and Oyedele, LO (2018) Critical Design Factors for Minimising Waste in Construction Projects: A Structural Equation Modelling Approach. Resources, Conservation and Recycling, 137. pp. 302-313. ISSN 0921-3449 DOI: https://doi.org/10.1016/j.resconrec.2018.06.005

Link to Leeds Beckett Repository record:

https://eprints.leedsbeckett.ac.uk/id/eprint/5044/

Document Version:

Article (Accepted Version)

The aim of the Leeds Beckett Repository is to provide open access to our research, as required by funder policies and permitted by publishers and copyright law.

The Leeds Beckett repository holds a wide range of publications, each of which has been checked for copyright and the relevant embargo period has been applied by the Research Services team.

We operate on a standard take-down policy. If you are the author or publisher of an output and you would like it removed from the repository, please contact us and we will investigate on a case-by-case basis.

Each thesis in the repository has been cleared where necessary by the author for third party copyright. If you would like a thesis to be removed from the repository or believe there is an issue with copyright, please contact us on openaccess@leedsbeckett.ac.uk and we will investigate on a case-by-case basis. 


\title{
Critical Design Factors for Minimising Waste in Construction Projects: A Structural Equation Modelling Approach
}

\author{
Ajayi, S. O.; Oyedele, L. O.
}

\begin{abstract}
Notwithstanding that efforts made at the design stage of building construction projects have significant impacts on project outcome, most waste management efforts are usually focussed on construction stage. This is albeit the understanding that construction waste could be significantly reduced through design activities. This study investigates the underlying design measures that are capable of minimising waste generated by construction and demolition activities. Using exploratory sequential mixed method research, the study employs focus group discussions and thematic analysis at the exploratory phase, while questionnaire and structural equation modelling were used at the explanatory stage of the study.

The study suggests that construction waste could be significantly reduced by designing for standard materials size and by designing for modern method of construction, thereby minimising waste due to breakage, materials leftover and other major causes of waste. The study further suggests that the design process and design documentation are key underlying measures for mitigating waste in construction projects. This could be enhanced through such critical success factors as a collaborative delivery process, which is characterised by early involvement of contractors and adequate coordination of design between various disciplines involved. Findings of this study would assist designers and other construction stakeholders in understanding the significant measures for designing out waste in construction projects.
\end{abstract}

Keywords: Dimensional coordination; modern method of construction; design out waste; structural equation modelling; design document; collaborative design.

\subsection{Introduction}

Waste generated by the construction and demolition activities is estimated at $44 \%$ of total waste to the UK landfill (DEFRA, 2013). This is more than double the proportion of waste generated by each of commercial, household, mining and industrial activities, which are estimated to contribute $14 \%, 13 \%$, 9\% and $13 \%$ respectively (DEFRA, 2013). This trend is similar to the patterns in other nations, as evidence suggests that the proportion of construction and demolition waste is up to $29 \%$ in the US (Yu et al., 2013), 25\% in Canada (Yeheyis et al., 2013) and 25\% in Hong Kong (Lu and Tam, 2013). Apart from cities running out of landfill site, waste landfilling has significant environmental impacts. While 
some wastes will finally decompose, others could provide various forms of pollution such as leaching into land and water as well as emission of various gaseous substances.

In addition to the negative impacts of waste generation, evidence suggests that reducing waste in construction projects has significant economic benefits. This would result in savings in forms of the cost of wasted materials, cost of storage, landfill tax, and cost of disposal (Coventry and Guthrie, 1998; Ajayi et al., 2015), which are usually shifted to the clients (Guthrie et al., 1999). A study by the UK's Building Research Establishment (BRE) suggests that up to $£ 130$ million could be saved by reducing just 5\% of its construction waste (BRE, 2003). Owing to the requisite of waste minimisation to the sustainable economy and the global sustainability agenda, the EU has introduced various legislative provisions to target waste reduction, minimisation, re-use and recycling. For instance, the EU Waste Framework Directive (2008/98/EC) currently sets a target of re-using, recycling and/or recovering 70\% of construction and demolition waste by 2020. The Circular Economy Package of the EU also sets a new target for recycling other forms of waste, with a binding landfill reduction target of $10 \%$ by 2030 ; thus, there is an increasing need to focus on waste mitigation.

Due to these significant benefits of waste minimisation, there has been a large body of knowledge on construction waste (e.g. Faniran and Caban, 1998; Formoso et al., 2002; Dainty and Brooke, 2004; Osmani et al., 2008; WRAP, 2009b, etc.). These sets of studies suggest that waste is caused by, and could be minimised through, activities ranging throughout the whole project lifecycle, including design, materials procurement and construction activities. Accordingly, there is an increasing awareness that rather than concentrating on site effort to reduce and manage waste during building construction activities waste minimisation should be considered throughout all stages of the building process design to completion (Ekanayake and Ofori, 2004). This is especially as a single stage-based measure would produce less waste minimisation outcome when compared to a holistic effort at the design, material procurement and construction stages of project delivery processes (Ding et al., 2018).

However, most construction waste management studies have largely focussed on the actual construction stage, resulting into the strategies for achieving the 3Rs - reduce, reuse and recycle (Osmani, 2012; Ajayi et al., 2017a). This is notwithstanding that waste management efforts at the construction stage is belated if the design and the whole design process is not waste-efficient, especially as up to $33 \%$ of building construction waste could be prevented through design activities (Innes, 2004). In line with this, the widely referred McLeamy curve recognised design stage as being a decisive stage with multiple implications for project outcome (McLeamy, 2004). It has critical impacts on key project performance indicators such as cost, time and quality, among others. In addition, the cost of change is cheaper if such change is made at the design stage of project delivery process (McLeamy, 2004). It is, therefore, 
important that construction waste management is approached from a design perspective, so as to corroborate the efforts made at the later stage of the project delivery processes. Such measures would provide the cheapest option for minimising waste generated by construction activities.

The overall aim of the study is to establish the key and underlying design measures for mitigating waste generated by the construction industry. The study seeks to explore and confirm a set of design measures that are capable of minimising waste generated by construction and demolition activities. The study fulfils its aim through the following sets of objectives.

1. To understand the key design measures for driving waste minimisation in construction projects.

2. To evaluate whether there are differences in perception of different professionals on design strategies for waste minimisation

3. To explore, model and establish the underlying sets of design strategies for waste-efficient construction projects.

The study adopts exploratory sequential mixed method approach, combining qualitative data collection and analysis at its first stage with quantitative data collection and structural equation modelling at its later stage. The first stage avails the study an opportunity to carry out an in-depth exploration of waste efficient design measures while the second stage of the study provides an opportunity for rigorous confirmation of the established strategies, using confirmatory factor analysis.

The next section of the paper provides a review of the literature on design strategies for construction waste mitigation. This is then followed by a section on the methodological approach to the study, justifying and explaining the data collection and analytical procedures for the qualitative and quantitative study. The conclusion and implication for practice section is preceded by the discussion of findings from statistical analysis and structural equation modelling. Findings of this study would assist designers and other stakeholders in understanding the measures for designing out waste in construction projects.

\subsection{Reducing waste through design}

The cost of making changes in construction projects is evident to be cheaper if such change is made at the design stage of project delivery process (McLeamy, 2004). In line with these benefits, evidence suggests that waste could be significantly reduced by taking waste preventive measures at the design stage. For instance, Osmani (2012) and Faniran and Caban (1998) suggest that most waste management 
studies tend to concentrate on construction stage while evidence shows that construction waste could be significantly reduced by taking care of several design factors that tend to impact waste (Ekanayake and Ofori, 2004). Innes (2004) also claimed that dedicated measures to reduce waste through design process could reduce total waste by up to a third. The earlier a change is implemented in a project lifecycle, the more its positive impact, and the less the cost of such change. This concept is similarly applicable to dedicated effort towards waste management. The earlier such effort, the more likely it would prevent waste occurring at a later stage.

Meanwhile, the attributes, competencies and dedication of designers and design management team are important in achieving low waste construction projects. Apart from design stage being a crucial stage for waste preventive effort, adverse environmental impacts of construction activities have been widely blamed on designers (Mansikkasalo et al., 2014). Technical capabilities of designers in terms of errorfree design, dimensional coordination and the use of standard detailing are recognised as pre-requisite for waste minimisation (Ekananyake and Ofori, 2004). Designers' knowledge of construction materials could also help in preventing early replacement of materials, which could, in turn, result in waste generation (Esin and Cosgun, 2007).

Design documentation has impacts on the effectiveness of the build process and waste generation (Gann et al., 2003). This is because, the design document could affect buildability of the projects while its accuracy and attention to detail could influence design error that could otherwise lead to reworks (Formoso et al., 2002). Ajayi et al. (2017b) suggest that the quality of design document for waste effectiveness could be described in terms of both the accuracy of information as well as completeness of the information provided. Specification of materials in devoid of over ordering and adequate coordination of designs from different professionals would determine the accuracy of the information (Begum et al., 2007). Design document such as deconstruction plan, waste management plan and bar bending lists, among others have also been suggested as additional drivers of waste minimisation in construction projects (Oyedele et al., 2013; Akinade et al., 2015).

The effectiveness of the whole design processes and coordination have effects on waste generated at the construction stage of project delivery (Osmani et al., 2008). This is in terms of the extent to which various specialities are coordinated, level of communication between parties as well as stakeholders' meetings, all of which are found to be important to waste prevention (Ikau et al., 2013; Al-Hajj and Hamani, 2011). Oyedele et al. (2013) suggest the need for an early involvement of contractors as well as design freeze before actual construction. However, it is not always possible to freeze the design before actual construction as design change is often initiated by the client who pays for both the project 
and the waste. Nonetheless, implementation of sustainable design appraisal system such as BREEAM means that attention would be paid to waste minimisation (Tam, 2008).

Improved buildability of design has been recognised as one of the key strategies for waste minimisation (Lovell, 2012). By adopting a modern method of construction such as prefabricated and dimensionally coordinated elements, buildability of design could be enhanced. In line with this, Formoso et al. (2002) suggest the use of preassembled components and modular coordination of building elements as means of reducing waste due to offcut and materials leftover. Standardisation and dimensional coordination of building elements such as the use of standard door and window, coordination of structural grid and planning grid designing for standard dimensions and units, and optimisation of tiles layout were found to reduce waste generated by construction activities (Dainty and Brooke, 2004; WRAP, 2009a).

Akinade et al. (2017) suggest that demolition waste contributes up to $50 \%$ of waste generated by the construction industry. As a means of reducing demolition waste to landfill, it is important that design and construction technique is responsive to change, while deconstructability should be considered during the design process. To achieve this, Oyedele et al. (2013) suggest designers should be encouraged to produce deconstruction plan during the design stage as this will guide deconstruction activities at the end of buildings' lifecycle. In addition, such initiative could ensure that substantial proportion of the building materials are recovered and reused at the end of buildings' lifecycle. Similarly, the design could assist in reducing waste due to building refurbishment and maintenance during its useful lifecycle. For instance, the specification of durable materials would reduce waste due to early replacement of materials and elements (Esin and Cosgun, 2017), while a flexible and adaptable design would ensure that spaces are reconfigured without much need for demolition (Yuan, 2013b). It is equally important that design and its processes are proactively analysed to identify and prevent, or at least minimise, activities that could contribute to waste during the actual construction project (Bilal et al., 2016).

\subsection{Research Methods}

Mixed method research, combining literature review, qualitative data and quantitative data collection and analyses, were used in the study. The first phase involved a review of the extant literature to identify design measures that can enhance waste minimisation in construction projects. This was then followed by qualitative data collection and analysis. In line with the procedure for exploratory sequential mixed method research (Creswell, 2014), the results from the first phase of the study formed the basis for the research instrument used for the quantitative study at the second stage. This section explains the methodological approach for the study. Figure 1 illustrates the methodological flow for the study. 


\subsection{Qualitative Sampling and Data collection}

Focus group discussions were used to elicit experts' opinion on design strategies for mitigating waste in construction projects. Unlike interviews, this method of data collection allows the participants to build on one another's opinion throughout the course of discussions (Kvale, 1996). As recommended by Merriam (1998), purposive sampling technique was used for reaching out the participants as it allows researchers to freely select information-rich participants to gain an in-depth understanding of the phenomenon under investigation. Two major sources that assisted in reaching out to the research participants are databases of certified construction professionals and a network of contacts.

In all, 30 participants were involved in four cross-disciplinary focus group discussions. The crossdisciplinary nature of the discussions avails the opportunity of establishing a common understanding of those involved from design to completion of construction projects.

Table 1: Overview of the focus group discussions and the participants

\subsection{Qualitative Analysis and Finding}

The qualitative data analysis followed the procedure for thematic analysis as suggested by Braun and Clarke (2006). This involved data familiarisation, coding and segmentation, development of themes and connection of interrelated themes. The coding and categorisation of the identified factors were based on dominant themes that emanated from individual and combined analysis of data from all focus group discussions in line with content driven thematic analysis (Creswell, 2002). After the use of coding system and theme identification as recommended by Silverman (2006), similar themes were mapped together to form broader themes. The themes explain more holistic measures that are generated by combining very similar factors emanating from the data. Table 2 combines the findings from the literature review with the results of the qualitative analysis.

Table 2: Design measures for mitigating construction waste 


\subsection{Quantitative Sampling and Data collection}

To test the wider applicability of the qualitative findings, a further quantitative data was collected through a questionnaire designed with the earlier findings. The established design factors were put on a five-point Likert Scale, where 5 represents most important and 1 represents not important. The questionnaire was pilot tested to ensure adequacy in the layout, clarity of language, the degree of depth and logic of question as suggested by Tashakkori and Teddlie (2010).

After improving the research instruments through comments obtained from the pilot study, the questionnaire was administered through both face-to-face, postage and online medium to reach wider participants. The research participants were largely drawn from a list of top $100 \mathrm{UK}$ construction firms, seven design and construction-related professional bodies as well as through the use of researchers' network of contact within the industry. In all, a total of 622 participants were invited for the quantitative data collection. After series of email reminders, 302 responses were received, representing a response rate of $48.6 \%$. Out of these, 17 questionnaires failed preliminary analysis through incomplete information and unengaged responses, and they were removed from further analysis. Based on this, 285 questionnaires were used for statistical analysis and the structural equation modelling. Table 3 shows the distribution of the research respondents.

\section{Table 3: Overview of the research respondents}

\subsection{Quantitative Data Screening and Reliability Analysis}

In order to prepare the data for further statistical analysis, some preliminary data screening and cleaning were carried out. This involved missing value analysis, detection of unengaged respondents, detection of outliers, and determination of multicollinearity. A quick overview of the dataset and calculation of standard deviation for each of the respondents shows that six of the respondents were unengaged, as their standard deviation returns a value close to zero. Hence, they were removed from further data analysis. As recommended by Kline (2010), Mahalanobis distance (D) statistic of the structural equation modelling was used to test for any influential outlier in the data. With no output having a P1 less than 0.05 , the finding suggests that there is no any significant outlier in the dataset.

Internal consistency of criteria contained in the questionnaire, as well as the suitability of the data for analysis, was evaluated using Cronbach's Alpha. With Cronbach's alpha ranging from 0 to 1 , a value of 0.7 represents an acceptable consistency (Nunnally and Bernstein, 2007). Results of the Cronbach's alpha for each category of variables are presented in Table 4. The Cronbach's alpha if item deleted 
suggested that some of the factors were not contributing to the overall reliability of the dataset; and as such, they were deleted from the list.

\subsection{Kruskal-Wallis Analysis}

Kruskal-Wallis test was used to determine whether job positions of the respondents affect the pattern by which they ranked the variables at $95 \%$ confidence level. The Kruskal-Wallis test for the significant difference was carried out on design factors to determine whether job positions affect the perception of the design measures for waste minimisation. As such, respondents' job positions were used as grouping variables, while the design factors were used as testing variables. As presented in Table 4, the KruskalWallis coefficient suggests that only one of the design factors was perceived differently by the respondents $(\mathrm{P}<0.05)$, representing $97.4 \%$ of agreement on the factors. Other factors have their $\mathrm{P}-\mathrm{Value}$ greater than 0.05 . This means that combining the responses of all the respondents will not affect overall reliability of the findings. Meanwhile, the only factor with differing perception is "involvement of contractors at early design stage" (DF4), which has a P-Value of 0.009. A further probe into the different groups' mean suggested that the factor was ranked high by project managers, site waste managers and civil/structural engineers, while architect/design managers posit that the factor is of less importance.

\section{Table 4: Non-parametric analysis of design measures}

\subsection{Use of Structural Equation Modelling}

Structural Equation Modelling (SEM) is a multivariate technique that is used for exploring and testing the relationship between variables. According to Hair et al. (2006), SEM encompasses regression analysis, factor analysis, multiple correlations and path analysis, making it a robust tool. In addition, SEM takes care of measurement error and it has capabilities for estimating and visually representing multiple interrelated relationships (Kline, 2010).

Due to its ability to estimate and visually represent multiple and interrelated variables, SEM has been used for investigating key design strategies for minimising waste in construction projects. A major benefit of using SEM in this study is that its Confirmatory Factor Analysis (CFA) helps in confirming the relationship between measured variables and waste-efficient design strategy as an independent variable. The tool helped in identifying the significant variable based on the magnitude of the established relationships between measured, first and second order variables.

\subsection{Development of Hypothetical Model}


In order to confirm the structure of factors underlying waste-efficient design, CFA was conducted on the design factors and its established dimensions. The six dimensions for designing out waste (as presented in Table 4) were modelled as first-order latent variables, and they consist of seven, eight, eight, four, two and two indicator (measured/observed) variables respectively. Apart from confirming the main indicators contributing to each of the latent variables, an important aspect of this study is to establish the relationship between the six dimensions and waste-efficient design. This helped to establish the key dimensions for designing out waste. Based on this requirement, two-step approach that combined measurement and structural models were used as suggested by Anderson and Gerbing (1998). Thus, the model consists of both structural and measurement models. Figure 2 shows specification for an initial model of the relationship between indicators, first-order and second-order variables.

\section{Figure 2: Initial/Hypothetical model of the design measures for waste minimisation}

\subsection{Model Fitness, validity and Reliability of Constructs}

In SEM, model fitness refers to the extent to which the data reflects the theory or propositions underlying the model. Based on its importance, several criteria for goodness of fit have been developed. These are generally in three categories, which are absolute fit, incremental fit and parsimonious fit (Xiong et al., 2014). Hair et al. (2010) suggests the use of alternative indices across the categories, especially the Chi-Square $\left(\mathrm{X}^{2}\right)$ and assumed differences, Root Mean Square Error of Approximation (RMSEA) and Comparative Fit Indices (CFI). Similarly, Kline (2010) recommends the use of ChiSquare $\left(\mathrm{X}^{2}\right)$, RMSEA, Global Fit Index (GFI), CFI, PCLOSE and Standardized Root Mean Square Residual (SRMR). In line with these recommendations, Normed Chi-Square, RMSEA, GFI and AGFI were used as measures of the absolute fit of the model. This study evaluates its incremental model fitness using NFI, NNFI and CFI, while the model was evaluated for Parsimonious fit through PGFI and PNFI. Table 5 shows the threshold for the fit indices.

\section{Table 5: Thresholds for model fit indices}

In order to evaluate the adequacy of the model regarding the relationship established between latent and observed (measured) variables, tests of validity and reliability are usually performed. These include face validity, discriminant validity of the measurement model and convergent validity of the measures associated with latent variables (Kline, 2010). Significant standardised factor loading was used to ensure the convergent validity of the model (Anderson and Gerbing, 1988). 


\subsection{Confirmatory Factor Analysis}

Confirmatory Factor Analysis was conducted to confirm the key underlying measures for mitigating waste through design. The total sample size is above the $\mathrm{N}=200$ threshold recommended by Kline (2010) for SEM, thus buttressing the suitability of the data for measurement and structural models. Models were developed with AMOS 22 for structural equation modelling. For the CFAs, the initial model was developed based on the factor established as presented in Tables 4 . The factors that failed the initial reliability test were removed as indicated in the tables. As recommended by Ullman (2001), Kline (2010) and numerous other experts, Maximum Likelihood (ML) technique was used for the model estimation. This is especially suitable as it yields maximum parameter estimate when used for normally distributed data of this nature (Ullman, 2001). Results of the covariance are assessed to test the appropriateness of the initial model, using fit indices discussed in the previous section.

Based on the evaluation of the initial model, improvements were required for adequate validity, reliability and model fitness with data. To improve the model fit, two methods were used for model modification. As suggested by Kline (2010), modification indices of SPSS AMOS (version 22) were used to add covariance and causal relationships between error terms and measured variables respectively. This approach is widely used for refining SEM and for improving its model fit (Chen et al., 2011). It was ensured that all modifications made theoretical sense concerning interrelationship between waste mitigation measures. In addition to the modification indices, the path diagram was screened to check for variables that show no significant correlation with latent factor and to check for any significant variable with low correlation coefficient. The hypothetical models went through series of refinement before the desired model fit, reliability and validity were achieved in each case.

Based on this, indicators with low factor loading and those with insignificant loadings were deleted from the model as suggested by Kline (2010). This affected one indicator (DF38) of the design document, two indicators (DF3 and DF12) of the design process and two indicators (DF16 and DF20) of design for modern methods of construction. After deleting the indicators, the model fit indices improved to a satisfactory level and five of the six dimensions for designing out waste passed the convergent validity test with their AVE ranging between 0.62 and 0.79 , which is above the 0.5 thresholds (Hair et al., 2008). All the loadings were also statistically significant. Figure 3 shows the final model, while Table 6 shows the construct reliability and variance extracted for all constructs of designing out waste.

Figure 3: Final Model of design measures for construction waste minimisation 
Table 6: Maximum Likelihood estimate and value of fit statistics for the design measures

\subsection{Discussion}

With design stage widely reckoned as being decisive for construction waste minimisation, this section discusses the design measures for driving low waste construction projects. The discussions are in three sections, which are based on the results of statistical analysis and Structural Equation Modelling (SEM). The first section discussed the findings of the Kruskal-Wallis test, as it provides the basis for combining the findings. The second section discusses five key design strategies for designing out waste based on results of descriptive statistics, while the last section addresses the underlying dimensions for designing out waste based on the final structural models of strategies for designing out waste.

\subsection{Test for Significant Difference on Design Measures}

The only factor with differing perception is "involvement of contractors at early design stage" (DF4), which has a P-Value of 0.009 . This finding suggests that while contractors and other site-based team believed that their input is invaluable at the design stage of project delivery process; designers believed that they independently possess skillsets required for designing out waste. However, evidence suggests that design could be responsible for about a third (33\%) of construction waste (Innes, 2004). This means that despite the acclaimed ability of designers in designing out waste, the design remains a major factor responsible for waste intensiveness of the construction industry. Oyedele et al. (2014) suggest that inadequate use of recycled products in the UK construction industry is partly due to poor consideration of the materials at the design stage. Apart from waste minimisation tendencies, evidence suggests that early involvement of contractors have positive impacts on drawing quality, information flow, materials supply and schedule performance (Song et al., 2009).

Considering the manufacturing industry where low waste is generated, there is more integration of design with manufacturing process (Koskela, 2004). This prevents the likelihood of "over-the-wall syndrome", a phenomenon that occurs due to poor collaboration among project participants (Chary, 1988). Notwithstanding the difference in experts' view of the early involvement of contractors, there is an agreement on several other factors requiring collaborative working system among project 
participants. For instance, there is a general agreement that the use of collaborative procurement route such as Integrated Project Delivery (IPD) is essential to reducing waste generated by the construction industry.

Based on this difference in perception, it could be inferred that unlike manufacturing industry, the construction is highly fragmented and each party prefers to work independently. This affects the ability of other parties to contribute their expertise, which in turns results in errors, reworks and subsequent waste generation. In line with this, Arain et al. (2014) suggest that non-involvement of the contractor at the design stage is responsible for errors in construction projects. Consequently, while designers are expected to collaborate with contractors during the construction stage, inputs from contractors can enhance the waste effectiveness of the design. Thus, there is a need for cultural and behavioural change from fragmented to a collaborative approach to project delivery.

\subsection{Underlying Dimensions for Designing out Waste}

Results of the Structural Equation Modelling shows that the 39 previously identified measures for designing out waste could be replaced by four key factors that were rigorously confirmed through Confirmatory Factor Analysis. These factors include:

- Design for modern methods of construction

- Waste-efficient design process

- Design for standardisation

- Waste-efficient design document

The four underlying factors have a significant proportion of their variance explained by waste-efficient design, and they are discussed in the next subsequent sections.

\subsubsection{Standardisation and dimensional coordination}

A key measure that loaded significantly with the waste-efficient design is standardisation and dimensional coordination, which has $77 \%$ of its variance explained by waste-efficient design. It is constituted by six measures for designing out waste, which are clear detailing, dimensional coordination, optimised layout, standardised fixtures, simplicity and overall standardisation. Dimensional coordination of design refers to a scenario whereby standard materials supplies are considered and taken into consideration during design. Coordination of design dimensions and specification of standard materials would not only improve constructability of buildings, but it would also help in preventing avoidable off-cuts, which could lead to waste. Constructability of a building is a key factor that measures the extent to which efficient construction is factored into the design and 
design processes (Mbamali et al., 2005). It has been reasoned that design teams are expected to take a leading role in ensuring buildability and constructability of their projects (Lam et al., 2006). Improved buildability of design is not only required for early project completion and resource efficiency (Lovell, 2012), it is a proven way through which construction waste could be reduced (Yeheyis et al., 2013; Yuan, 2013b).

Crawshaw (1976) suggests that a discrepancy of $10 \mathrm{~mm}$ in one dimension would not only affect contractors' programmes, but it could also cost up to $£ 3,000$ in reworks. As such, it is important that while the error is prevented in dimension, the design should also be standardised to avoid unnecessary offcuts. In a similar note, WRAP (2009a) recommends standardisation of building forms and layout and the use of full height doors as a means of reducing construction waste. This is in line with this study, which posits that apart from preventing errors in design, individual elements of the buildings are to be standardised based on the market size of the materials. For instance, window and glazing area, as well as door openings, should be appropriately sized.

In line with this study, other authors have also recommended dimensional coordination and standardisation of building elements as an optimal means of reducing construction waste (Dainty and Brookes, 2004; Baldwin et al., 2007). It is expected that buildings are designed in response to site topography to avoid excavation waste (Yuan, 2013b), complex designs are adequately detailed to improve buildability (Nagapan et al., 2013) and structural grid and planning grid are properly coordinated (WRAP, 2009a). Thus, it is not only important that designers address dimensional coordination of the building elements, spaces and elements need to be standardised in design. This would result in a reduction of both construction and end of life waste.

Another benefit of dimensional coordination and standard materials supplies is the ability to reuse the materials at the end of buildings' life cycle, aligning with the concepts of the circular economy (MolinaMoreno et al., 2017). To reduce waste generated by the construction industry, designers' waste management measures should go beyond immediate construction activities and current use to which the building is put. It is important that buildings be designed for flexibility and change, in a way that building modification and change in spatial configuration will result in minimal waste. This is particularly necessary as evidence suggests that substantial proportion of waste generated by the construction industry is because of renovation works (Esin and Cosgun, 2007).

\subsubsection{Collaborative Design Process}

Early collaboration and improved communication during the design process is confirmed as a key approach for designing out waste in construction projects. The SEM of design strategies in Figure 8.2 
shows that design process is a key dimension for designing out waste, with a $\beta$ value of 0.91 at $99.9 \%$ confidence level. The five key contributing factors that were confirmed in the final model pointed towards collaborative design arrangement that engenders adequate information sharing and communication among the project team.

Due to its fragmented and dynamic nature, construction activities usually involve series of errors capable of influencing project success. When an error occurs, it leads to reworks, which in turns affect project cost and results in waste. Although the cost of reworks has significantly reduced from $30 \%$ around the 1970s (Crawshaw, 1976), it could still account for about 5\% of project costs (Hwang et al., 2012). Rework is one of the major activities that contribute to waste intensiveness of the construction industry (Faniran and Caban, 1998; Ekanayake and Ofori, 2004). Although design change might not be totally prevented in construction, increasing collaborative working has a tendency of preventing errorinduced design change and reworks (Osmani, 2012). This could be achieved by involving the contractors at the early design stage to contribute to design decisions, materials specification and technology. Dainty and Brooke (2004) suggests that most error at construction stage is usually due to contractors' poor knowledge of the design and its documentation. This results in an insufficient understanding of design, and as such, results in an error. Thus, involving contractor in the design process would not only benefit the design, but it would also equally enhance contractors' understanding of project requirements and design documents.

The SEM suggests that a key factor that defines Waste-efficient design process is adequate communication between various specialities involved in the design. Typically, design input is made by various professionals within the built environment, involving architects, civil/structural engineers and M\&E engineers among others. To ensure adequate coordination of design from various specialities involved, as well as to prevent design clash, there is a need for effective communication among the parties (Domingo et al., 2009). This further buttresses the importance of collaboration right from the design stage, as collaborative procurement routes are characterised by improved communication and adequate information sharing.

Meanwhile, the need to improve collaboration in the construction industry has engendered various procurement route and digital platforms, among which BIM and Integrated Project Delivery are becoming increasingly required (Ilozor and Kelly, 2011). While IPD is underpinned by integration of people and every aspect of the project to harness insights and inputs for project optimisation, BIM is a technologically driven collaborative platform for enhancing digital representation, collaboration, production, storage and sharing of building information (Eastman et al., 2011). Thus, apart from the likelihood of preventing immediate clash and other causes of waste (Bilal et al. 2015), increased 
collaboration would enhance information sharing and early collaboration among project stakeholders, thereby foreseeing and preventing likely causes of waste.

\subsubsection{Design for Modern Methods of Construction (MMC)}

Design for Modern Method of Construction (MMC) is confirmed as a key dimension for designing out waste, with a $\beta$ value of 0.68 at $99.9 \%$ confidence level. It also has $74 \%$ of its variance explained by waste efficiency in design, suggesting that it is a good reflector of the extent by which waste is designed out in a construction project. MMC usually refers to building construction technique whereby buildings are factory manufactured and site assembled (Lovell, 2012). It involves a situation whereby various components of buildings are manufactured in a controlled factory environment and are transported to the site, where the components are assembled. Innovative onsite building technologies are also sometimes referred to as MMC (Mohd Nawi et al., 2014). The result of SEM shows that designing for MMC is a key dimension for designing out waste. These measures include designing for modular construction, prefabrication and preassembled components as well as the use of modern low waste techniques such as drywall partitions (Baldwin et al., 2007).

This finding is also buttressed by earlier studies, which posit that adoption of modern methods of construction, such as offsite construction and prefabrication of building components, significantly reduces construction waste (Cf. Dainty and Brooke, 2004; Al-Hajj and Hamani, 2011).

In addition to its tendencies for waste minimisation during construction, MMC supports constructability and de-constructability of buildings (Formoso et al., 2002; Oyedele et al., 2013). This could ensure that building elements are reused after the end of its lifecycle, as the elements are appropriately sized to conventional standards. For instance, bathroom or kitchen pods could be diligently removed and reused in another building. It is, therefore, important that designers consider the MMC while designing, as the methods are proven waste-efficient (Yuan, 2013a).

\subsubsection{Waste-efficient design Documentation}

Another reflector of Waste-efficient design is the quality and comprehensiveness of design document, which has a $\beta$ value of 0.65 at $99.9 \%$ confidence level, with $72 \%$ of its variance explained by the latent factor. The quality of design documents has great impacts the on the overall effectiveness of the build process (Gann et al., 2003). It is a key requisite for preventing waste generated by construction 
activities. For instance, design errors and wrong detailing have a tendency of resulting in construction errors, which will in turns lead to reworks (Faniran and Caban, 1998). As such, completeness and accuracy of design documents is important for reducing waste generated by construction activities. This is because; design documents do not only affect buildability of the project, its comprehensiveness and accuracy would go a long way in preventing errors that could lead to reworks (Formoso et al., 2002). Therefore, it is not only important that design documents provide adequate information, but it is also required that it employs conventional language and incorporates all features that are site specific. It is vital that design documents are legibly presented in a consistent detailing language and format, easily understood by all trades involved in the project lifecycle.

Specification as an important document has a decisive influence on the waste output of construction project. Oyedele et al. (2003) considered inadequate specification as a major cause of waste in construction projects. If over-ordering, under-ordering and over-allowance were well addressed in schedule and specification document, less waste would be generated on construction sites. It is, therefore, important that design and specification documents be accurately prepared to prevent waste that could arise from deficiencies in design documentation. In addition, evidence suggests that design document usually lack some essential details required for successful construction exercise, thereby leaving the contractors with guesswork and subsequent waste generation (Begum et al., 2007). It is expected that adequate design information is provided in the design document to ensure that subsequent businesses are carried out with less waste (Khanh and Kim, 2014).

Similarly, current industry practices lack provision for preparation of deconstruction plan, which would not reduce waste generation during construction but become a vital document for demolition and end of life waste diversion from landfill. The deconstruction plan is an important document for reducing waste intensiveness of the construction industry, as building demolition waste constitutes a larger portion of total waste generated by the construction industry. Designing for deconstruction is recognised as one of the five spectrums through which waste could be designed out in construction projects (WRAP, 2009a). It involves careful planning, designing and selection of building materials in such a way that buildings support the selective demolition of its elements (Saghafi and Teshnizi, 2011). Careful planning for buildings to support deconstruction at the end of its lifecycle, and subsequent availability of deconstruction plan, would reduce waste generated by the industry. This finding buttressed earlier studies by Oyedele et al. (2013) which suggests that to reduce landfill waste, there is a need for deconstruction plan to become part of design documentation. Thus, a major attribute of Waste-efficient design is the extent to which deconstruction has been factored into it. 


\subsection{Conclusion and Implications for Practice and Policy Making}

This section summarises the findings of the study. The implications of the study for practice, policy making, theory and future research directions are also presented in the section.

\subsection{Summary of the Study and Findings}

Most construction waste management studies have been focussed on the construction stage of project delivery processes, despite the overwhelming evidence that waste is caused by activities throughout the project lifecycle, including design, procurement and construction stages. As the cost of change in a construction project is cheaper if it is implemented at the design stage, this study explored and confirmed the design strategies for mitigating waste generated by construction and demolition activities. The study employed exploratory sequential mixed method research, involving the use of qualitative and quantitative studies at the first and second stages respectively. Qualitative data was collected using focus group discussions, which was subsequently analysed through thematic analysis. At the later stage of the study, the quantitative data was collected through a questionnaire designed from the findings of the earlier study, and its analysis was performed using descriptive statistics, Kruskal-Wallis test and structural equation modelling.

Findings of the study show that the industry experts agreed on all but one design measures for waste mitigation. While the project managers, site waste manager, civil/structural engineers and other expert groups believe that their early involvement during the design stage is essential for waste minimisation, the architects and design managers are of the view that such collaborative working approach is not a requisite for waste mitigation. Findings from the structural equation modelling suggested that Standardisation and dimensional coordination, Collaborative Design Process, Design for Modern Methods of Construction (MMC) and waste-efficient design Documentation are the underlying measures for mitigating waste through design.

\subsection{Implications for Practice and Policy Making}

Findings of this study have significant implications for design practices and other activities involved in the project delivery processes. While seeking to design out waste, the focus of designers should be on optimisation of building design in line with standard materials supplies. This specifically becomes the key driving force when a project does not involve prefabricated construction method. Designing for standard material supplies would not only enhance buildability of the design, it would also help in preventing avoidable off-cuts, which could lead to waste. At the project level, design process usually involves inadequate coordination and poor collaboration among design professionals. Rather than the usually fragmented approach, this study suggests the need for an integrated approach to both the design process and throughout the whole project delivery process. Gaining more importance in the construction 
industry is the use of BIM for design coordination. Use of this technique would enhance collaboration required for driving waste minimisation through design activities. It is also essential that other project stakeholders are involved early in the design process, not only for their expertise to shape the design but also for them to have a good understanding of the design, thereby preventing errors and reworks due to poor understanding of design.

Apart from designing for standard materials supply, the study shows that designing for modern methods of construction such as the use of offsite construction techniques and modular construction are essential for minimising waste in construction projects. Earlier evidence suggests that this approach could reduce waste by up to $80 \%$, and the approach aligns with the collaborative arrangement as every stakeholder are usually involved at an early stage of projects when prefabricated elements are largely used. Such collaborative approach and the use of prefabrication techniques could bring the construction industry close to the level of manufacturing industry, where error and waste are significantly reduced as a result of enhanced collaboration. It will equally enhance the accuracy and completeness of the design document, which is also evident to contribute to waste intensiveness of the construction industry.

\subsection{Theoretical Implications of the Study}

With the consideration of design stage for waste mitigation, this study is one of the few studies that have specifically focussed on the design stage as the decisive stage for tackling waste in construction projects. Its use of the Structural Equation Modelling also lends strength to the finding, which identifies the key design measures for designing out waste in construction projects. Based on its findings, the study theoretically implies that decisions related to "autonomation" are the most significant measure for driving waste minimization through design. Through the SEM, design for standardization, prefabrication and collaboration were confirmed as the key drivers of construction waste minimisation. This confirms the relevance of Lean construction theory, which advocates for increased use of prefabrication, standardization and improved collaborative process.

Basically, the study mirrors the rising clamour for improved collaboration among construction professionals. As a result of poor collaboration, there is a poor project coordination and shifting of waste management responsibility among project stakeholders. This results in errors, reworks and subsequent waste generation. Rather than concentrating on waste at the individual level, there is need to drive project waste minimisation through collaborative procurement and contractual clauses. This would engender commitments to waste minimisation among project participants. Interestingly, the result of Kruskal-Wallis test indicates the while other stakeholders believe in their early involvement as a way of driving waste minimization, the designers do not share the same view. While this could be as a result of the perception that it challenges their professionalism, there is an overwhelming evidence that an 
early involvement of contractors and other project stakeholders have positive impacts on drawing quality, information flow, materials supply and schedule performance. It would, therefore, be interesting to investigate the reasons for designers' reluctance to early collaboration with other stakeholders.

\subsection{Limitations and Implications for Future Academic Research}

As earlier stated, this study has been carried out in the UK. Other studies could investigate generalisability of its findings to the global construction industry by collecting data from other countries and comparing its findings with this study. Such approach would help to understand whether there is a regional difference in the strategy for mitigating construction waste through design. Similarly, as this study covers only building projects, future research could specifically investigate strategies for minimising waste in civil engineering projects. This would allow comparison of strategies for waste minimisation in building and civil engineering projects. In addition, case studies of construction projects could be carried out to further investigate and quantify the impacts of the identified measures on construction waste output.

Although the design stage is evident to be capable of minimising a substantial proportion of construction waste, the waste is caused by activities occurring throughout the whole process of project delivery processes. While this study has established the design measures for mitigating waste, the proportional significance of design stage has not been addressed. Further study could, therefore, investigate the extent to which waste could be reduced by measures taken at each of planning, design, material procurement and actual construction stage of the project lifecycle. Such study would help to understand the strategic importance of each stage for construction waste mitigation. It is also important the future studies consider the whole stages of project delivery processes, incorporating the design, materials and actual construction activities.

\section{References}

Ajayi, S.O., Oyedele, L.O., Bilal, M., Akinade, O.O., Alaka, H.A., Owolabi, H.A. and Kadiri, K.O., 2015. Waste effectiveness of the construction industry: Understanding the impediments and requisites for improvements. Resources, Conservation and Recycling, 102, pp.101-112.

Ajayi, S. O., Oyedele, L. O., Bilal, M., Akinade, O. O., Alaka, H. A., \& Owolabi, H. A. 2017a. Critical management practices influencing on-site waste minimization in construction projects. Waste Management, 59, 330-339. 
Ajayi, S.O., Oyedele, L.O., Akinade, O.O., Bilal, M., Alaka, H.A., Owolabi, H.A. and Kadiri, K.O., 2017b. Attributes of design for construction waste minimization: A case study of waste-to-energy project. Renewable and Sustainable Energy Reviews, 73, pp.1333-1341.

Akinade, O.O., Oyedele, L.O., Bilal, M., Ajayi, S.O., Owolabi, H.A., Alaka, H.A. and Bello, S.A., 2015. Waste minimisation through deconstruction: A BIM based Deconstructability Assessment Score (BIM-DAS). Resources, Conservation and Recycling, 105, pp.167-176.

Akinade, O.O., Oyedele, L.O., Omoteso, K., Ajayi, S.O., Bilal, M., Owolabi, H.A., Alaka, H.A., Ayris, L. and Looney, J.H., 2017. BIM-based deconstruction tool: Towards essential functionalities. International Journal of Sustainable Built Environment.

Al-Hajj, A. \& Hamani, K., 2011. Material Waste in the UAE Construction Industry: Main Causes and Minimization Practices. Architectural Engineering and Design Management, 7(4), pp. 221 - 235.

Arain, F. M., Assaf, S. \& Pheng, L. S., 2004. Causes of discrepancies between design and construction. Architectural Science Review, 47(3), 237-249.

Begum, R. A., Siwar, C., Pereira, J. J. \& Jaafar, A. H., 2007. Implementation of waste management and minimisation in the construction industry of Malaysia. Resources, Conservation and Recycling, 51(1), pp., 190-202.

Bilal, M., Oyedele, L.O., Qadir, J., Munir, K., Akinade, O.O., Ajayi, S.O., Alaka, H.A. and Owolabi, H.A., 2015. Analysis of critical features and evaluation of BIM software: towards a plug-in for construction waste minimization using big data. International Journal of Sustainable Building Technology and Urban Development, 6(4), pp.211-228.

Bilal, M., Oyedele, L. O., Akinade, O. O., Ajayi, S. O., Alaka, H. A., Owolabi, H. A., ... \& Bello, S. A. (2016). Big data architecture for construction waste analytics (CWA): A conceptual framework. Journal of Building Engineering, 6, 144-156.

Braun, V., and Clarke, V., 2006. Using thematic analysis in psychology. Qualitative research in psychology, 3(2), pp. 77-101.

BRE, 2003. Construction and demolition waste: Good buildings guide 57 Part 1. UK: Building Research Establishment

Chary, S.N., 1988. Production and operations management. Tata McGraw-Hill.

Chen, Y.Q., Zhang, Y.B., Liu, J.Y. \& Mo, P., 2011. Interrelationships among critical success factors of construction projects based on the structural equation model. Journal of Management in Engineering, 28(3), pp.243-251.

Coventry, S. \& Guthrie, P., 1998. Waste minimization and recycling in construction: Design manual. London: CIRIA.

Crawshaw, D. T., 1976. Coordinating working drawings. UK: Building Research Establishment.

Creswell, J. W., 2002. Educational research: Planning, conducting, and evaluating quantitative and qualitative approaches to research. Upper Saddle River, NJ: Merrill/Pearson Education 
Creswell, J. W., 2014. Research design: Qualitative, quantitative, and mixed methods approaches, $4^{\text {th }}$ edition. Thousand Oaks, CA: Sage.

Dainty, A.R.J. \& Brooke, R.J., 2004. Towards improved construction waste minimisation: A need for improved supply chain integration? Structural Survey, 22(1), pp., 20-29.

Department for Environment, Food and Rural Affairs (Defra, 2013). Waste Prevention Programme for England: Overview of Evidence-A rationale for waste prevention in England. London: Defra.

Ding, Z., Zhu, M., Tam, V.W., Yi, G. and Tran, C.N., 2018. A system dynamics-based environmental benefit assessment model of construction waste reduction management at the design and construction stages. Journal of Cleaner Production, 176, pp.676-692.

Domingo, N., Osmani, M. \& Price, A. D., 2009 Construction waste minimisation in the UK healthcare industry. In: Dainty, R.J. (Ed.). Proceedings of the 25th Annual ARCOM Conference, 7-9 September 2009, Albert Hall, Nottingham. Association of Researchers in Construction Management, Vol. 2, pp. 1021-30.

Eastman, C., Teicholz, P., Sacks, R. \& Liston, K., 2011. BIM Handbook: A guide to Building Information Modelling for Owners, managers, Designers, Engineers, and Contractors. New Jersey: John Wiley and sons

Ekanayake, L.L. \& Ofori, G., 2004. Building waste assessment score: Design-based tool. Building and Environment, 39(7), pp. 851-861.

Esin, T. \& Cosgun, N., 2007. A study conducted to reduce construction waste generation in Turkey. Building and Environment, 42(4), pp. 1667-1674.

Faniran O.O, \& Caban G., 1998. Minimizing waste on construction project sites. Engineering, Construction and Architectural Management, 5(2), pp. 182-188.

Field, A. P., 2009. Discovering statistics using SPSS (and sex and drugs and rock ' $n$ 'roll). London: Sage

Formoso, C.T., Soibelman, L., De Cesare, C. \& Isatto, E.L., 2002. Material Waste in Building Industry: Main Causes and Prevention. Journal of Construction Engineering and Management, 128(4), pp. $316-325$.

Gann, D., Salter, A. \& Whyte, J., 2003. Design quality indicator as a tool for thinking. Building Research and Information, 31(5), pp. 318-333.

Guthrie, P.M., Coventry, S.J. \& Woolveridge, A.C., 1999. Waste minimization and recycling in construction: Technical review. London: CIRIA.

Hair, J.F., Black, W.C., Babin, B.J. \& Anderson, R.E., 2010. Multivariate data analysis: A global perspective, $7^{\text {th }}$ edition. Upper Saddle River, NJ: Prentice Hall

Hozo, S.P., Djulbegovic, B. and Hozo, I., 2005. Estimating the mean and variance from the median, range, and the size of a sample. BMC medical research methodology, 5(1), p.13. 
Hwang, B. G., Thomas, S. R., Haas, C. T., \& Caldas, C. H. (2009). Measuring the impact of rework on construction cost performance. Journal of Construction Engineering and Management, 135(3), 187-198.

Ikau, R., Tawie, R., and Joseph, C., 2013. Initial findings on perspectives of local contractors on waste minimization barriers and incentives on construction sites. In: proceeding of 2013 IEEE Business Engineering and Industrial Applications Colloquium (BEIAC), pp. 506 - 509.

Ilozor, B. D. \& Kelly, D. J., 2011. Building Information Modeling and Integrated Project Delivery in the Commercial Construction Industry: A Conceptual Study. Journal of Engineering, Project, and Production Management, 2(1), 23-36.

Innes, S., 2004. Developing tools for designing out waste pre-site and onsite. In: Proceedings of Minimising Construction Waste Conference: Developing Resource Efficiency and Waste Minimisation in Design and Construction, New Civil Engineer, London, UK, October 2004.

Khanh, H.D. \& Kim, S.Y., 2014. Identifying Causes for Waste Factors in High-Rise Building Projects: A Survey in Vietnam. KSCE Journal of Civil Engineering, 18(4), pp. 865-874

Kline, R.B., 2010. Principles and practice of structural equation modelling, $3^{\text {rd }}$ edition. New York: Guilford publications.

Koskela, L. J. 2004. Making do-the eighth category of waste. In: Proceeding of the 12th Annual Conference of the International Group for Lean Construction (IGLC-12), Elsinore, Denmark, 2004

Kvale, S., 1996. InterViews: An introduction to qualitative research interviewing. CA: Sage

Lam, P.T., Wong, F.W. \& Chan, A.P., 2006. Contributions of designers to improving buildability and constructability. Design Studies, 27(4), pp.457-479.

Li, J., Tam, V.W., Zuo, J. and Zhu, J., 2015. Designers' attitude and behaviour towards construction waste minimization by design: A study in Shenzhen, China. Resources, Conservation and Recycling, 105, pp.29-35.

Lu, W. and Tam, V.W., 2013. Construction waste management policies and their effectiveness in Hong Kong: A longitudinal review. Renewable and sustainable energy reviews, 23, pp.214-223.

Lovell, H., 2012. Modern Methods of Construction. In: Smith, S.J. (Ed.). The Elsevier International Encyclopedia of Housing and Home, vol.4, pp. 312-316.

Mansikkasalo, A., Lundmark, R. \& Söderholm, P., 2014. Market behavior and policy in the recycled paper industry: A critical survey of price elasticity research. Forest Policy and Economics, 382014, pp. 17-29.

Mbamali, I., Aiyetan, O.A. \& Kehinde, J.O., 2005. Building design for buildability: an investigation of the current practice in Nigeria. Building and environment, 40(9), pp.1267-1274.

McLeamy, P., 2004. Integrated Project Delivery: McLeamy Curve.

Merriam, S. B., 1998. Qualitative research and case study applications in education. Revised and expanded from case study research in education. San Francisco: Jossey-Bass 
Mohd Nawi, M.N., Lee, A., Noor, M., Azman, A. \& Mohamad Kamar, K.A., 2014. Fragmentation issue in Malaysian industrialised building system (IBS) projects. Journal of engineering Science and Technology.

Molina-Moreno, V., Leyva-Díaz, J.C., Sánchez-Molina, J. and Peña-García, A., 2017. Proposal to Foster Sustainability through Circular Economy-Based Engineering: A Profitable Chain from Waste Management to Tunnel Lighting. Sustainability, 9(12), p.2229.

Nagapan, S., Rahman, I.A., Asmi, A., Memon, A.H, \& Zin, R.M., 2012. Identifying causes of construction waste - Case of central region of Peninsula Malaysia. International Journal of Integrated Engineering, 4(2), pp. 22-28

Norman, G., 2010. Likert scales, levels of measurement and the "laws" of statistics Advances in health sciences education, 15(5), pp.625-632.

Nunnally, J.C. \& Bernstein, I.H., 2007. Psychometric Theory, $3^{\text {rd }}$ edition. New York: McGraw-Hill

Osmani, M., 2012. Construction waste minimization in the UK: Current pressures for change and approaches. Procedia - Social and Behavioral Sciences, 402012, pp. 37-40.

Osmani, M., Glass, J. \& Price, A.D.F., 2008. Architects' perspectives on construction waste reduction by design. Waste Management, 28(7), pp. 1147-1158.

Oyedele, L. O., Ajayi, S. O. \& Kadiri, K. O., 2014. Use of recycled products in UK construction industry: An empirical investigation into critical impediments and strategies for improvement. Resources, Conservation and Recycling, 932014, pp. 23-31.

Oyedele, L.O., Regan, M., Meding, J.V., Ahmed, A., Ebohon, O.J. \& Elnokaly, A., 2013. Reducing waste to landfill in the UK: Identifying impediments and critical solutions. World Journal of Science, Technology and Sustainable Development, 10(2), pp. 131 - 142.

Saghafi, M. D. \& Teshnizi, Z. A. H., 2011 Building deconstruction and material recovery in Iran: An analysis of major determinants. Procedia Engineering, 21(2011), pp. 853-863.

Silverman, D., 2006. Interpreting qualitative data: Methods for analyzing talk, text and interaction, $3^{\text {rd }}$ edition. London: Sage.

Song, L., Mohamed, Y. \& AbouRizk, S.M., 2009. Early contractor involvement in design and its impact on construction schedule performance. Journal of Management in Engineering, 25(1), pp.12-20.

Tam, V.W.Y., 2008. On the effectiveness in implementing a waste-management-plan method in construction, Waste Management, 28(6), pp. 1072-1080.

Tashakkori, A. \& Teddlie, C., Eds., 2010. SAGE Handbook of mixed methods in social and behavioural research, $2^{\text {nd }}$ edition. Thousand Oaks: SAGE.

Ullman, J.B., 2001. Structural equation modelling. In: Tabachnick, B.G. \& Fidell, L.S. (Eds), Using Multivariate Statistics. Needham Heights, MA: Allyn \& Bacon, pp. 68-91.

WRAP, (2009a). "Designing out waste: A design team guide for buildings" (online). Available at: http://www.modular.org/marketing/documents/DesigningoutWaste.pdf. [Accessed: $3^{\text {rd }}$ March, 2014] 
WRAP, (2009b). "Delivering higher recycled content in construction projects" (online). Available at: http://www.wrapni.org.uk/sites/files/wrap/Delivering\%20higher\%20recycled\%20content\%20in $\% 20$ construction\%20projects.pdf. [Accessed: $5^{\text {th }}$ January, 2014].

Xiong, B., Skitmore, M. \& Xia, B., 2015. A critical review of structural equation modeling applications in construction research. Automation in Construction, 49, pp.59-70.

Yeheyis, M., Hewage, K., Alam, M.S., Eskicioglu, C. \& Sadiq, R., 2013. An overview of construction and demolition waste management in Canada: A lifecycle analysis approach to sustainability. Clean Technologies and Environmental Policy, 15(1), pp. 81 - 91.

Yu, A.T.W., Poon, C.S., Wong, A., Yip, R. and Jaillon, L., 2013. Impact of Construction Waste Disposal Charging Scheme on work practices at construction sites in Hong Kong. Waste management, 33(1), pp.138-146.

Yuan, H., 2013. Key indicators for assessing the effectiveness of waste management in construction projects. Ecological Indicators, 242013, pp. 476-484.

Yuan, H., 2013b. Critical management measures contributing to construction waste management: Evidence from construction projects in china. Project Management Journal, 44(4), pp. 101-112. 
Table 1: Overview of the focus group discussions and the participants

\begin{tabular}{|c|c|c|c|c|}
\hline$F G$ & Categories of the Participants & Total No of experts & Years of experience & Duration (in minutes) \\
\hline 1 & $\begin{array}{l}\text { - } 2 \text { architects and design managers } \\
\text { - } 2 \text { structural/civil engineers } \\
\text { - } 1 \text { site waste manager } \\
\text { - } 2 \text { project managers } \\
\text { - } \quad 1 \text { Others** }\end{array}$ & 8 & $7-26$ & 111 \\
\hline 2 & $\begin{array}{l}\text { - } 2 \text { architects and design managers } \\
\text { - } 1 \text { structural/civil engineer } \\
\text { - } 1 \text { site waste manager } \\
\text { - } 2 \text { project managers } \\
\text { - } 1 \text { Others** }\end{array}$ & 7 & $11-23$ & 102 \\
\hline 3 & $\begin{array}{l}\text { - } 2 \text { architects and design managers } \\
\text { - } 1 \text { structural/civil engineer } \\
\text { - } 2 \text { site waste managers } \\
\text { - } 2 \text { project managers } \\
\text { - } 1 \text { Others** }\end{array}$ & 8 & $10-27$ & 119 \\
\hline 4 & $\begin{array}{l}\text { - } 2 \text { architects and design managers } \\
\text { - } 1 \text { structural/civil engineer } \\
\text { - } 1 \text { site waste manager } \\
\text { - } 2 \text { project managers } \\
\text { - } 1 \text { Others** }\end{array}$ & 7 & $9-25$ & 120 \\
\hline
\end{tabular}

** "Others" refers to sustainability experts, supply chain managers and lean practitioners in construction. 
Table 2: Design measures for mitigating construction waste

\begin{tabular}{|c|c|c|c|c|c|}
\hline \multirow{2}{*}{ Design Measures for reducing construction waste } & \multirow[t]{2}{*}{ References from extant literature } & \multicolumn{4}{|c|}{ Focus Groups } \\
\hline & & 1 & 2 & 3 & 4 \\
\hline \multicolumn{6}{|c|}{ Design Document Quality for Low Waste Projects } \\
\hline Drawing documents are free of errors to prevent reworks & Gann et al. (2003) & $\checkmark$ & $\checkmark$ & & $\checkmark$ \\
\hline Detailed specification devoid of under/over ordering & Begum et al. (2007); Oyedele et al. (2003) & $\checkmark$ & $\checkmark$ & $\checkmark$ & \\
\hline Designs from all trades are adequately coordinated/integrated & Al-Hajj and Hamani (2011) & & & $\checkmark$ & $\checkmark$ \\
\hline Drawings and other documents are legible & Baldwin et al. (2007) & $\checkmark$ & & $\checkmark$ & $\checkmark$ \\
\hline Consistency in detailing language/format & Osmani (2013) & & $\checkmark$ & & $\checkmark$ \\
\hline Waste management plan to be prepared along with design & Garas et al. (2010) & $\checkmark$ & $\checkmark$ & $\checkmark$ & \\
\hline Deconstruction plan as part of design documents & Oyedele et al. (2013) & & $\checkmark$ & $\checkmark$ & $\checkmark$ \\
\hline Waste scenario planning & & $\checkmark$ & $\checkmark$ & & $\checkmark$ \\
\hline Completeness: Adequate design information for subsequent businesses & Negapan et al. (2013); Khanh \& Kim (2009) & $\checkmark$ & & & $\checkmark$ \\
\hline Bar bending list as part of documentations & Al-Hajj and Hamani (2011) & & & & \\
\hline \multicolumn{6}{|c|}{ Efficacy of Design Process } \\
\hline Careful Coordination of contract documents to prevent error & Osmani et al. (2008) & $\checkmark$ & $\checkmark$ & $\checkmark$ & \\
\hline Early completion of contract documents before construction & Osmani et al. (2008) & $\checkmark$ & & $\checkmark$ & $\checkmark$ \\
\hline Ensure design freeze at the end of design process & Oyedele et al. (2013); Negapan et al. (2013) & $\checkmark$ & $\checkmark$ & $\checkmark$ & $\checkmark$ \\
\hline Involvement of contractors at early stage & Oyedele et al. (2013) & $\checkmark$ & $\checkmark$ & $\checkmark$ & $\checkmark$ \\
\hline Clearly specified project goal to avoid flawed planning/design & Faniran and Caban (1998) & & & & $\checkmark$ \\
\hline Pre-design meetings of key stakeholders & Oyedele et al. (2003) & & & & $\checkmark$ \\
\hline Early collaborative agreement before design activities & Osmani (2013) & $\checkmark$ & & $\checkmark$ & $\checkmark$ \\
\hline Economic incentives and enablers & Osmani (2013) & $\checkmark$ & & $\checkmark$ & \\
\hline Adequate coordination of various specialities involved in the design process & Ikau et al. (2013) & $\checkmark$ & & & $\checkmark$ \\
\hline Timeliness: Early distribution of design documents & Nagapan et al. (2013) & & & & \\
\hline Design management to prevent over specification of materials & Dainty and Brooke (2004) & & & & \\
\hline Adequate communication between trades & Domingo et al. (2009); Al-Hajj \& Hamani (2011); Osmani (2013) & $\checkmark$ & $\checkmark$ & $\checkmark$ & $\checkmark$ \\
\hline Adequate implementation of sustainable building assessment procedure & Tam (2008); Yeheyis et al. (2013) & & $\checkmark$ & & $\checkmark$ \\
\hline Drawings and other details are adequately coordinated between design discipline & Al-Hajj and Hamani (2011); Yuan (2013b) & & $\checkmark$ & $\checkmark$ & \\
\hline \multicolumn{2}{|c|}{ Design for Modern Methods of Construction } & & & & \\
\hline
\end{tabular}




\begin{tabular}{|c|c|c|c|c|c|}
\hline \multirow{2}{*}{ Design Measures for reducing construction waste } & \multirow[t]{2}{*}{ References from extant literature } & \multicolumn{4}{|c|}{ Focus Groups } \\
\hline & & 1 & 2 & 3 & 4 \\
\hline Specification of prefabricated materials & Yuan $(2013 a)$ & $\checkmark$ & $\checkmark$ & $\checkmark$ & $\checkmark$ \\
\hline Modular coordination of building elements & Formoso et al. (2002); Oyedele et al. (2003) & $\checkmark$ & $\checkmark$ & $\checkmark$ & $\checkmark$ \\
\hline Design for preassembled components & Formoso et al. (2002) & $\checkmark$ & & & $\checkmark$ \\
\hline Specify the use of efficient framing techniques & Osmani et al. (2008) & $\checkmark$ & $\checkmark$ & $\checkmark$ & \\
\hline Employ Modular design principles & Baldwin et al. (2007); Esin and Cosgun (2007) & $\checkmark$ & $\checkmark$ & $\checkmark$ & $\checkmark$ \\
\hline Specify the use of drywall partitioning and joint system & & $\checkmark$ & & $\checkmark$ & $\checkmark$ \\
\hline Design with buildability/constructability of the project in mind & Yeheyis et al. (2013); Yuan (2013b); Oyedele et al. (2003) & $\checkmark$ & $\checkmark$ & $\checkmark$ & $\checkmark$ \\
\hline \multicolumn{6}{|c|}{ Standardisation and Dimensional Coordination } \\
\hline Careful integration of building sub-system & Formoso et al. (2002) & & & $\checkmark$ & $\checkmark$ \\
\hline Ensure simplicity and clarity of detailing & Ekanayake and Ofori (2004); Domingo et al. (2009) & & & & \\
\hline Design for standard dimensions and units & Osmani et al. (2008) & $\checkmark$ & $\checkmark$ & $\checkmark$ & $\checkmark$ \\
\hline Standardise building forms and layout & WRAP, (2009a); McKechnie and Brown (2007); & & $\checkmark$ & $\checkmark$ & $\checkmark$ \\
\hline Ensure drawings consider and integrate site topography and existing utilities & Yuan (2013b); WRAP (2009) & $\checkmark$ & $\checkmark$ & $\checkmark$ & $\checkmark$ \\
\hline Dimensional coordination and standardisation of building elements & Dainty \& Brooke (2004); Baldwin et al. (2007); Ekanayake \& Ofori (2004) & $\checkmark$ & $\checkmark$ & $\checkmark$ & $\checkmark$ \\
\hline Optimize tile layout in conformity with design shape & WRAP $(2009 a)$ & $\checkmark$ & & & $\checkmark$ \\
\hline Use full height door or door with fanlight to avoid cutting plasterboard & WRAP (2009a) & $\checkmark$ & & & \\
\hline Standardise doors, windows and glazing areas & WRAP (2009a) & $\checkmark$ & & $\checkmark$ & \\
\hline Avoidance of overly complex design, where possible & Yuan $(2013 b)$ & & $\checkmark$ & $\checkmark$ & \\
\hline Ensure adequate detailing of complex design & Ekanayake \& Ofori (2004); Yuan (2013b); Baldwin et al. (2007) & & $\checkmark$ & $\checkmark$ & $\checkmark$ \\
\hline Coordinate structural grid and planning grid to avoid offcuts/conflict & WRAP (2009a) & & & & \\
\hline \multicolumn{6}{|c|}{ Design flexibility } \\
\hline Specification of collapsible elements for flexibility & & $\checkmark$ & $\checkmark$ & $\checkmark$ & $\checkmark$ \\
\hline Specify materials and joint system that support disassembly & WRAP (2009a) & $\checkmark$ & $\checkmark$ & $\checkmark$ & $\checkmark$ \\
\hline Design for changes and flexibility & Yuan $(2013 b)$ & $\checkmark$ & $\checkmark$ & $\checkmark$ & \\
\hline \multicolumn{6}{|c|}{ Organic design } \\
\hline Drawings consider and integrate existing site utilities & & $\checkmark$ & & $\checkmark$ & $\checkmark$ \\
\hline Drawings consider and integrate site topography & & & & & \\
\hline
\end{tabular}


Table 3: Overview of the research respondents

\begin{tabular}{|l|l|l|l|}
\hline Item/Variables & \multicolumn{1}{|c|}{ Groups/Labels } & Frequency & Percentage \\
\hline \multirow{4}{*}{ Job roles/titles } & Architects/design managers & 72 & 25.3 \\
\cline { 2 - 4 } & Civil/Structural Engineers & 56 & 19.6 \\
\cline { 2 - 4 } & Project managers & 96 & 33.7 \\
\cline { 2 - 4 } & Site waste managers & 16 & 5.6 \\
\cline { 2 - 4 } & Others & 45 & 15.8 \\
\hline \multirow{4}{*}{$\begin{array}{l}\text { Years of experience } \\
\text { years) }\end{array}$} & $1-5$ & 31 & 10.9 \\
\cline { 2 - 4 } & $6-10$ & 54 & 18.9 \\
\cline { 2 - 4 } & $11-15$ & 104 & 36.5 \\
\cline { 2 - 4 } & $16-20$ & 64 & 22.5 \\
\cline { 2 - 4 } & $21-25$ & 16 & 5.6 \\
\cline { 2 - 4 } & Above 25 & 16 & 5.6 \\
\hline
\end{tabular}




\begin{tabular}{|c|c|c|c|}
\hline Label & Design factors for driving waste-efficient projects & $\begin{array}{l}\text { Cronb. } \\
\text { Alpha }\end{array}$ & $\begin{array}{c}\text { Kruskal- } \\
\text { Wallis } \\
\text { coeff. }\end{array}$ \\
\hline $\boldsymbol{A}$ & Waste-efficient design documentation & & \\
\hline DF1 & Design are free of error & \multirow{10}{*}{0.797} & .574 \\
\hline$* D F 8$ & Include waste management into assessment of stakeholders & & .463 \\
\hline DF29 & Produce disassembly and deconstruction plan & & .427 \\
\hline DF33 & Specifications are detailed $\&$ devoid of under/over ordering & & .579 \\
\hline DF34 & Waste management plan is prepared along with design & & .891 \\
\hline DF35 & Drawings and other details are devoid of clash & & .573 \\
\hline$* D F 36$ & Bar bending list is prepared as part of documentations & & .262 \\
\hline DF37 & Drawing and specifications are written in conventional lang. understood by all & & .186 \\
\hline DF38 & Drawing documents are legible & & .552 \\
\hline$* D F 39$ & Waste scenario planning & & .704 \\
\hline B & \multicolumn{3}{|l|}{ Waste-efficient design Process } \\
\hline DF2 & Completion of contract documents before construction process & \multirow{10}{*}{0.932} & .605 \\
\hline DF3 & Design freeze at the end of design process & & .764 \\
\hline DF4 & Involvement of contractors at early design stage & & $.009 * * *$ \\
\hline$* D F 5$ & Pre-design meetings of key stakeholders & & .169 \\
\hline DF6 & Early collaborative agreement before design activities & & .279 \\
\hline$* D F 7$ & Give economic incentives and enablers to designers & & .254 \\
\hline DF9 & Adequate coordination of various specialities involved & & .496 \\
\hline DF11 & Improved communication between various specialities & & .198 \\
\hline DF12 & Implementation of sustainable building assessment procedure (such as BREEAM) & & .761 \\
\hline DF13 & Drawings and other details are coordinated between design disciplines & & .282 \\
\hline C & \multicolumn{3}{|l|}{ Design for standardization and dimensional coordination } \\
\hline DF14 & Detailing of the building elements is simple and clear & \multirow{11}{*}{0.859} & .301 \\
\hline$* D F 15$ & Complex designs are adequately detailed & & .780 \\
\hline DF16 & Building forms and layout are standardised & & .583 \\
\hline DF18 & Coordinate dimensions of building elements & & .645 \\
\hline DF19 & Tiles layout is optimised in conformity with design shape & & .480 \\
\hline DF20 & Specify the use of full height door or doors with fanlight & & .141 \\
\hline DF21 & Standardise doors, windows and glazing areas & & .176 \\
\hline DF22 & Avoid overly complex design & & .958 \\
\hline$* D F 31$ & Carefully integrate building sub-system & & .280 \\
\hline$* D F 32$ & Coordination of structural grid and planning grid & & .412 \\
\hline DF41 & Design for standard dimensions and units & & .365 \\
\hline$D$ & \multicolumn{3}{|l|}{ Design for Modern Methods of Construction } \\
\hline DF23 & Specification of prefabricated structural materials & \multirow{4}{*}{0.801} & .803 \\
\hline DF24 & Design for preassembled components e.g. bathroom pods & & .942 \\
\hline DF25 & Employ volumetric modular design principles & & .343 \\
\hline DF26 & Specify the use of drywall partitions (e.g. timber walling) & & .411 \\
\hline $\begin{array}{l}\boldsymbol{E} \\
\end{array}$ & \multicolumn{3}{|l|}{ Design for flexibility } \\
\hline DF28 & Design for collapsible and easily demountable components & \multirow{2}{*}{0.937} & .703 \\
\hline DF30 & Specify the use of joint system without glueing and nailing & & .212 \\
\hline$F$ & \multicolumn{3}{|l|}{ Organic Design } \\
\hline DF10 & Drawings consider and integrate existing site utilities & \multirow{2}{*}{0.716} & .393 \\
\hline DF17 & Drawings consider and integrate site topography & & .784 \\
\hline
\end{tabular}

*denotes factors that have "Cronbach's Alpha if item deleted" above their individual groups' Cronbach's Alpha, suggesting that the factors should be deleted to enhance and standardise the groups' reliability.

***denotes factors having significant Kruskal-Wallis coefficient at $95 \%$ confidence level. This means that respondents differ in their perception of the factor based on their job position. This affected only DF4 on the Table. 
Table 5: Thresholds for model fit indices

\begin{tabular}{|l|l|}
\hline Goodness of fit measures & ${\text { Recommended level of GOF } \text { measures }^{\boldsymbol{a}}}$ \\
\hline $\mathrm{X}^{2} /$ degree of freedom & $<5$ (preferably 1 to 2$)$ \\
\hline RMSEA & $<0.10$ (preferably $<0.08)$ \\
\hline Goodness of Fit Index (GFI) & 0 (no fit) -1 (perfect fit) \\
\hline Adjusted Goodness of Fit Index (AGFI) & (no fit) -1 (perfect fit) \\
\hline Comparative Fit Index (CFI) & (no fit) -1 (perfect fit) \\
\hline Normed Fit Index (NFI) & (no fit) -1 (perfect fit) \\
\hline Tucker-Lewis Index (TLI) & (no fit) -1 (perfect fit) \\
\hline Parsimonious Goodness of Fit Index (PGFI) & (no fit) -1 (perfect fit) \\
\hline Parsimonious Normed of Fit Index (PNFI) & (no fit) -1 (perfect fit) \\
\hline
\end{tabular}

a: Thresholds adapted from Kline (2010); Hair et al. (2010) and Chen et al. (2011). 
Table 6: Maximum Likelihood estimate and value of fit statistics for the design measures

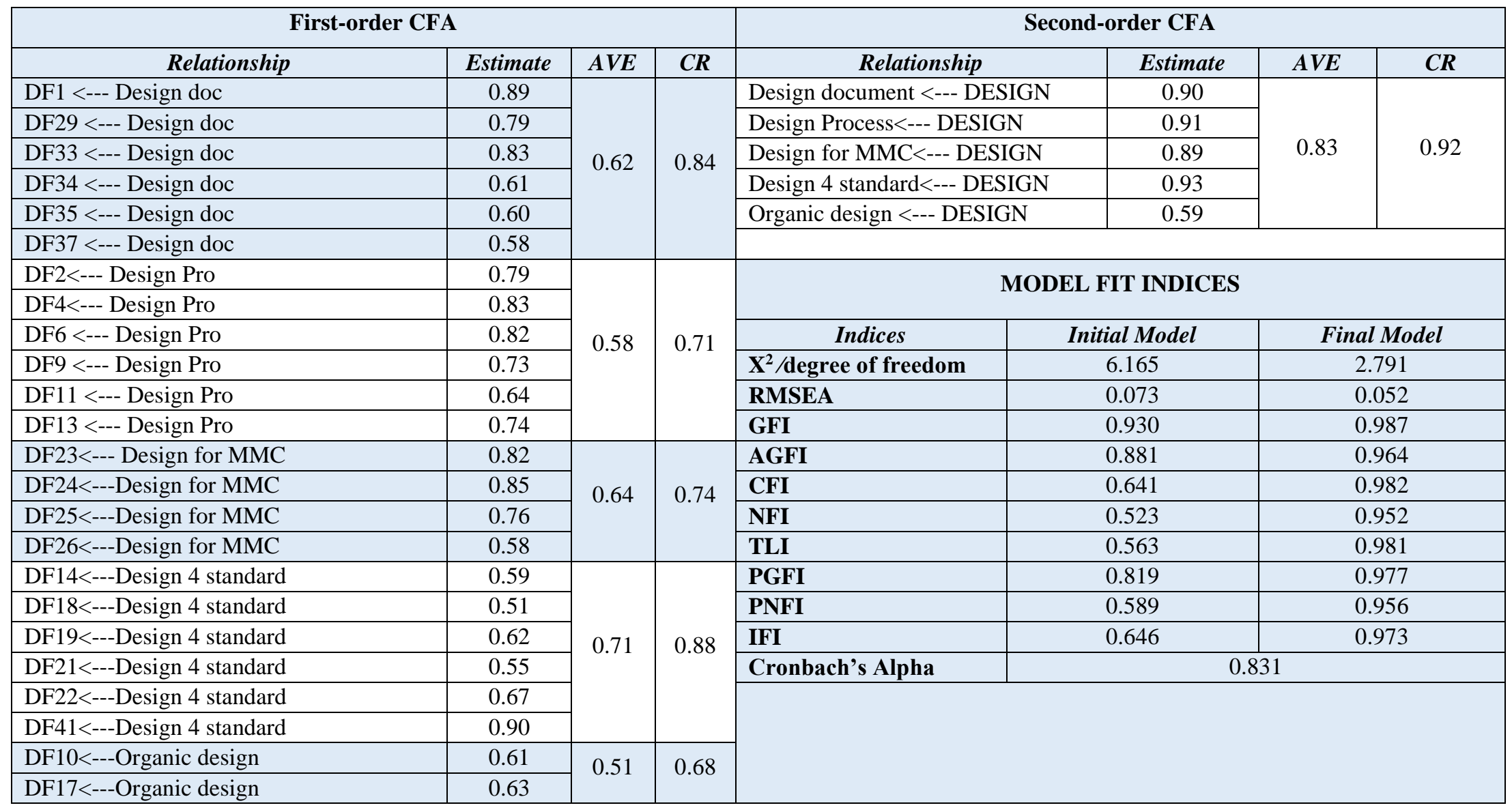




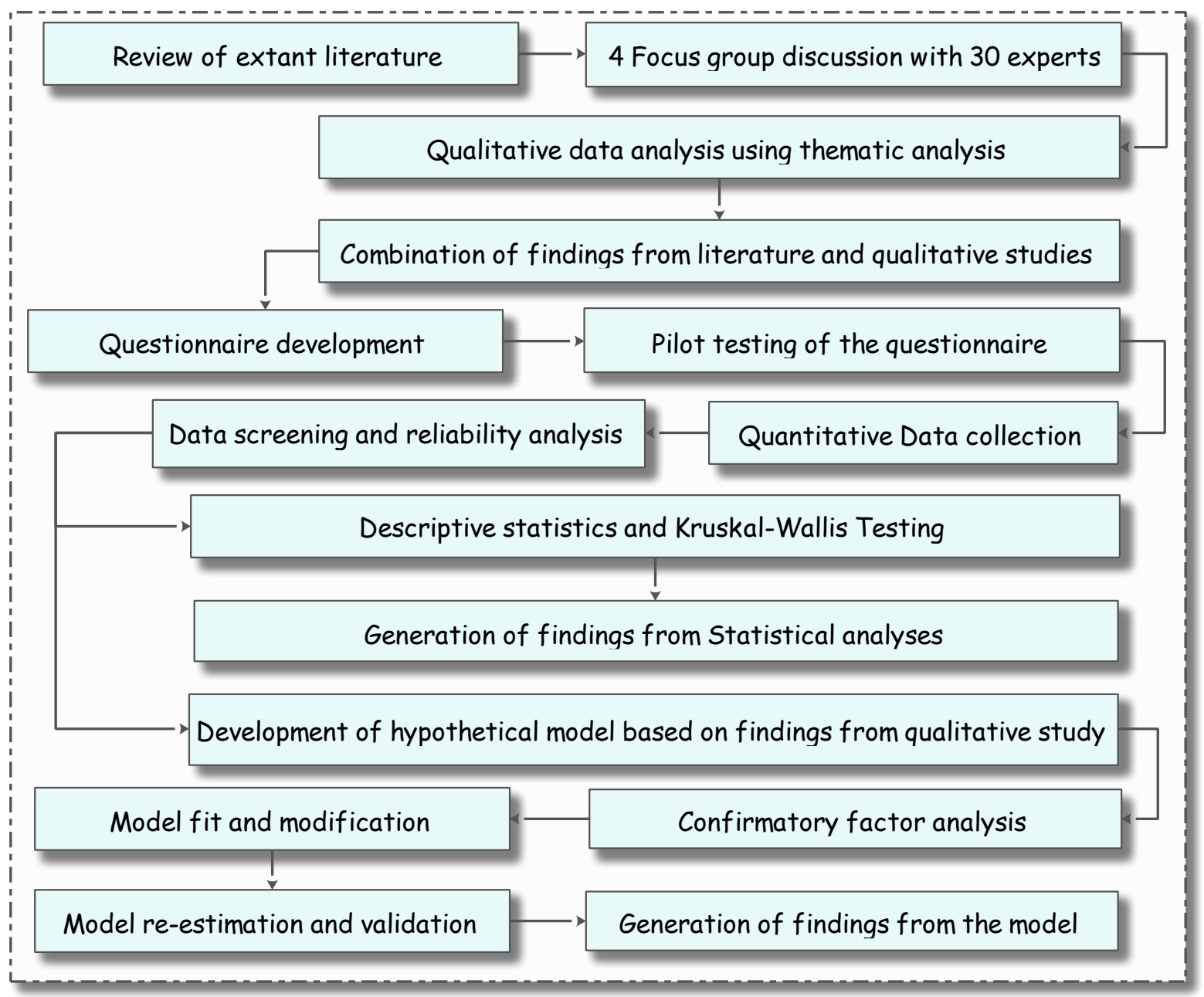

Figure 1: Methodological Flow Chart for the Study 


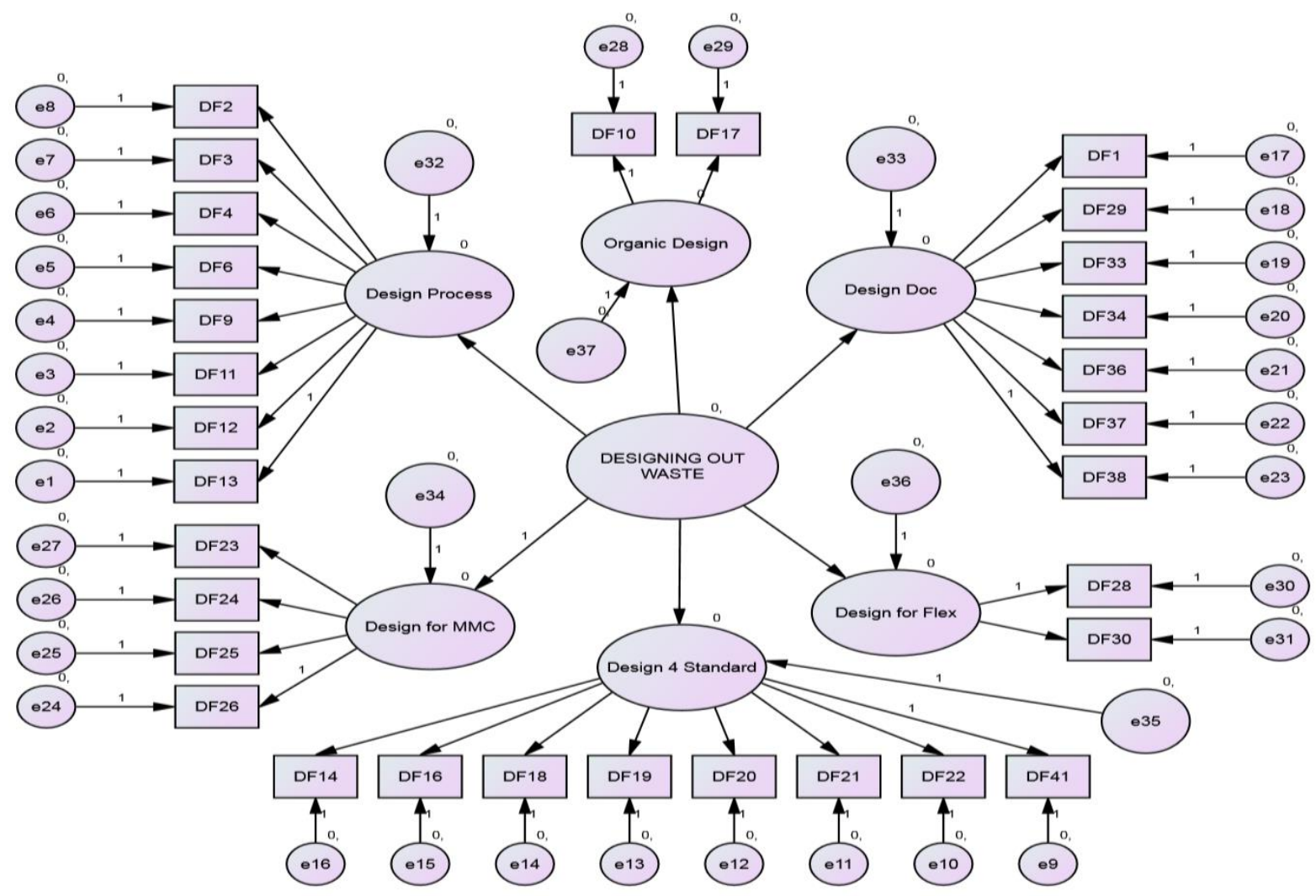

Figure 2: Initial/Hypothetical model of the design measures for waste minimisation

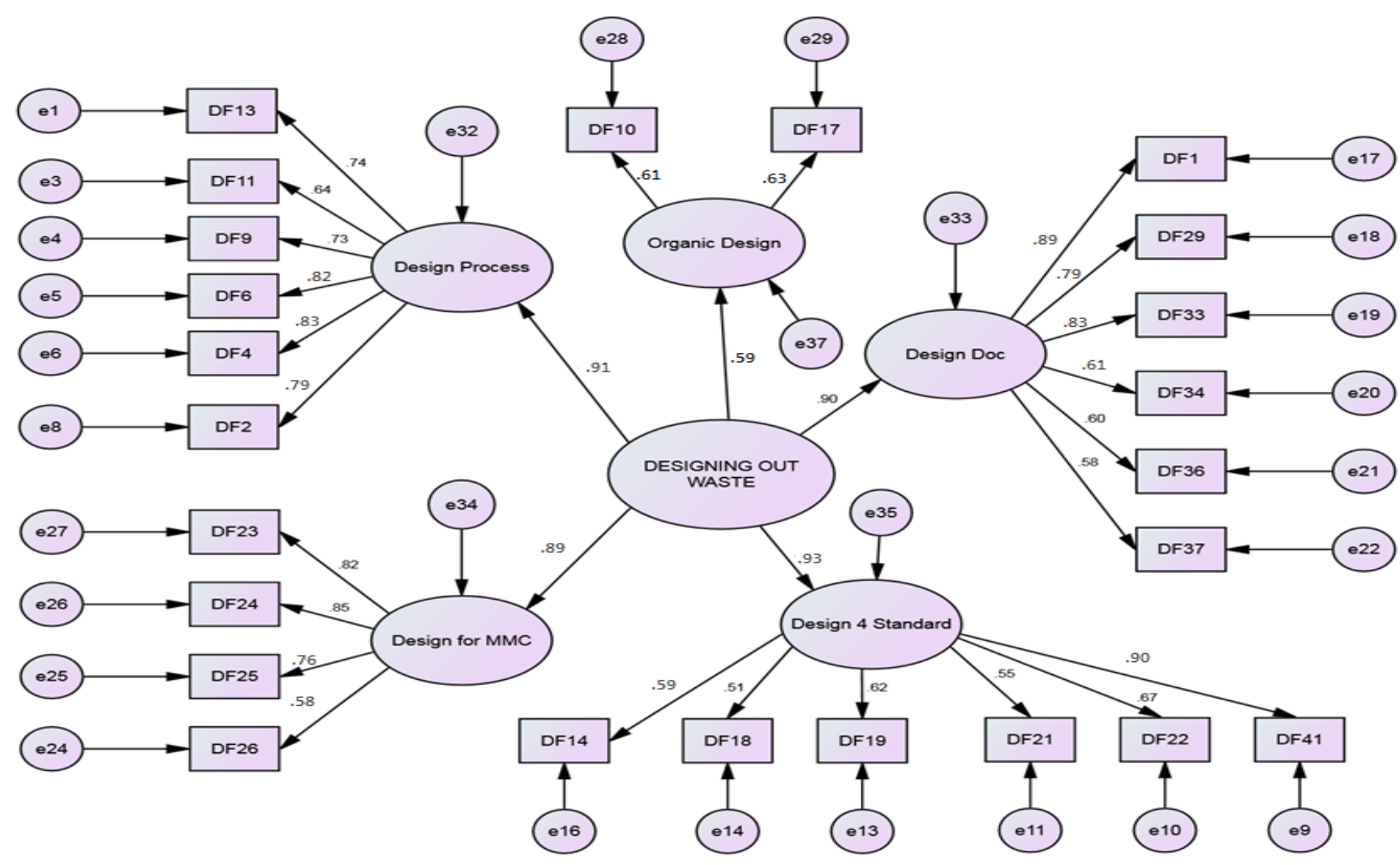

Figure 3: Final Model of design measures for construction waste minimisation 